Article

\title{
Behavioral and Biochemical Effects of Mukia madrespatana Following Single Immobilization Stress on Rats
}

\author{
Noreen Samad ${ }^{1, *}$, Amna Ali ${ }^{1}$, Farzana Yasmin ${ }^{2,3}$, Riaz Ullah ${ }^{4}$ (D) and Ahmed Bari 5 \\ 1 Department of Biochemistry, Bahauddin Zakariya University, Multan 60800, Pakistan; \\ amnaali394@gmail.com \\ 2 Department of Biomedical Engineering, NED University of Engineering and Technology, \\ Karachi 75270, Pakistan; farzanayasminpk@yahoo.com \\ 3 Department of Food Engineering, NED University of Engineering and Technology, Karachi 75270, Pakistan \\ 4 Department of Pharmacognosy (MAPPRC), College of Pharmacy, King Saud University, \\ Riyadh 12372, Saudi Arabia; rullah@ksu.edu.sa \\ 5 Central Laboratory, College of Pharmacy, King Saud University, Riyadh 12372, Saudi Arabia; \\ abari@ksu.edu.sa \\ * Correspondence: noreen.samad@bzu.edu.pk
}

Received: 22 June 2020; Accepted: 13 July 2020; Published: 14 July 2020 updates

\begin{abstract}
Background and Objectives: Elevated oxidative stress has been shown to play an important role in the diagnosis and prognosis of stress and memory-related complications. Mukia madrespatana (M. madrespatana) has been reported to have various biological and antioxidant properties. We intended to evaluate the effect of $M$. madrespatana peel on single immobilization stress-induced behavioral deficits and memory changes in rats. Materials and Methods: M. madrespatana peel (2000 mg/kg/day, orally) was administered to control and immobilize stressed animals for 4 weeks. Anxiolytic, antidepressant, and memory-enhancing effects of $M$. madrespatana were observed in both unstressed and stressed animals. Results: Lipid peroxidation was decreased while antioxidant enzymes were increased in both unstressed and stressed animals. Acetylcholine level was increased while acetylcholinesterase activity was decreased in both $M$. madrespatana treated unstressed and stressed rats. There was also an improvement in memory function. Serotonin neurotransmission was also regulated in $M$. madrespatana treated rats following immobilization stress with anxiolytic and anti-depressive effects. Conclusion: Based on the current study, it is suggested that M. madrespatana has strong antioxidant properties and may be beneficial as dietary supplementation in stress and memory-related conditions.
\end{abstract}

Keywords: Mukia madrespatana; oxidative stress; stress; memory; antioxidant enzymes

\section{Introduction}

Stress is a major threat to the body that alters homeostasis at the cellular level. The immobilization stress model is an easy and continent method for inducing both psychological and physical stresses in mammals [1]. Stress may lead to a variety of central nervous system irregularities that include anxiety, depression, learning, and memory functions [2]. According to earlier reports, there is restricted mobility, an anxiety-like effect, and deterioration of antioxidant enzyme activities following immobilization stress [3].

The activation of hypothalamic pituitary adrenal (HPA)-axis by a stress situation induced greater release of glucocorticoid, which damaged neurons and their functions [4]. The increased levels of glucocorticoid stimulated the release of glutamate in the cortex and limbic part of the brain [5]. The 
increased neuronal flow of glutamate can harm mitochondria and enhance cellular respiration [6]. This increase in cellular respiration generated additional free radicals, causing an unevenness between pro-oxidant and antioxidant defense system [7,8]. Free radicals resulted in oxidative harm at the cellular level and damaged cellular machinery [9]. The brain is a very sensitive organ because of its high content of readily oxidized fatty acids, high expenditure of oxygen, and low antioxidant levels [10]. Additionally, free radicals are produced constantly as an entailment of normal metabolic functions. The increased free radicals' production and weak antioxidant defense system have been associated with serious neurological ailments including depression, dementia, Alzheimer's disease, etc. However, enhancement in the antioxidant defense system can combat the increased free radical production and control/protect the body from a variety of threats [11,12].

Extensive studies reported that natural antioxidants may be useful against stress-instigated neuronal complications $[13,14]$. Medicinal plants play a vital role in therapeutics. There is a growing interest in plant-based therapy from a few years back due to its natural origin and minimum adverse effects $[15,16]$. At present, clinical trials are underway to evaluate the protective effects of medicinal plants against neurological disorders, i.e., depression, Alzheimer's, Parkinsonism, etc. Biologically-active components present in the medicinal plants made them useful for treating various diseases. Bio-activity of the plants having medicinal potential is related to bioactive components, i.e., alkaloids, flavonoids, polyphenols, tannins, triterpenoids, coumarins, and glycosides [14-16].

Mukia madrespatana (M. madrespatana) (L.) M. Roem. (Cucurbitaceae), which is commonly known as the Madras pea pumpkin, is one such plant [17], with distribution throughout the tropics and subtropics of the Old World [18]. Phytochemistry of M. madrespatana discovered the presence of phenolic, tannins, flavonoids, alkaloids, and saponins. These phytochemical compounds in M. madrespatana are strong-reducing agents due to their abundant $\mathrm{OH}$ groups that enhance their antioxidant activity [19]. Various in-vitro and in-vivo studies have been conducted with the M. madrespatana plant. It was reported that it has anti-inflammatory, antiarthritic [20], anti-asthmatic, antitussive, antihistaminic, anti-bronchitic [21], antihypertensive, and anti-diabetic [22] effects due to its powerful antioxidant potential.

Taking into consideration in the first part of the present study, various doses of M. madrespatana peel powder were used to evaluate the exploratory activity of rats in the novel and familiar environment, via various behavioral analyses, to select a potential dose for further experiments. In the second part of the study, anti-stress, antioxidant, and memory-enhancing effects of the selected dose of $M$. madrespatana peel powder were evaluated following acute immobilization stress. Before starting the experimental procedure, acute toxicity of M. madrespatana in animals was monitored.

\section{Materials and Methods}

\subsection{Animals}

In the present work, adult male Albino Wistar rats (weighing 160-180 gm, eight weeks old) were locally bred and utilized in this study. Rats were housed in an individual cage (with static racks) to keep away from the social contact effect because social contact can influence behavioral analysis of animals. The Albino Wistar rats were given a standard rodent diet (A control diet $(4.47 \mathrm{kcal} / \mathrm{g}$ ) containing $25 \%$ fat, $50 \%$ carbohydrate, and 25\% protein [23]) and drinking water under a controlled temperature $\left(20 \pm 5{ }^{\circ} \mathrm{C}\right)$ and a 12-hour light/dark cycle. Before starting the experimental work, rats experienced seven days of acclimation time and different conduct measures to diminish the stress of newness and treatment. The Institutional Ethical Committee (Ref \# D-1991/1-Biochem; Dated: September 29, 2018) approved all experiments. Additionally, all experiments were performed in strict accordance with the National Institute of Health Guide for Care and Use of Laboratory Animals (Publication No. 85-23, revised 1985). 


\subsection{Plant Material and Chemicals}

Fresh fruits of Mukia maderaspatana (M. madrespatana) were collected from the area of the field near Multan City, Pakistan. The plant material was recognized and authenticated by the taxonomist (Dr. Zafar Ullah Zafar, Department of Botany, Bahauddin Zakariya University, Multan) and a voucher (R.R. Stewart F.W. Pak.706 (3)) was retained in an herbarium. Fresh fruits of M. madrespatana were washed and peeled off. Peel of M. madrespatana was air-dried at room temperature and then ground into a fine powder using an electric grinder and stored in an airtight container. The selection of low and high doses of $M$. madrespatana fruit peel powder in the present study based on the previous report in which the whole plant of $M$. madrespatana with various extracts (aqueous and ethanolic) was used with various dosages, i.e., 100-200 mg/kg body weight [24] and $2000 \mathrm{mg} / \mathrm{kg}$ body weight [25,26]. The required amount of powder was weighed and mixed well in deionized water $(3 \mathrm{~mL})$ and fed to animals by the gavage technique. Every time a fresh drug dose was prepared for oral administration. All chemicals used in the current study were purchased from Chemical Co. Sigma-Aldrich, St. Louis, MO, USA.

\subsection{Acute Toxicity Test}

The toxicity procedure was performed as reported previously [27]. Twelve animals $(n=4)$ were used for the acute toxicity test as reported previously [28]. Two sets of rats $(n=4)$ were accommodated overnight in a fasting condition with tap water and food was withdrawn for 4-5 h after oral intake of M. madrespatana fruit peel powder. Starting a dose of $125 \mathrm{mg} / \mathrm{kg}$ body weight was given to the first set and a maximum dose of $2000 \mathrm{mg} / \mathrm{kg}$ body weight was given to the second set. The third set of rats $(n=4)$ was drinking tap water and all the rodents were observed individually. Clinical signs were examined. Body posture, tremors, locomotion, pain response, vocalization, body weight, water intake, etc. were also observed. No death was seen with given doses. According to Economic Co-operation and Development (OECD) guidelines, the LD50 value considered above $125 \mathrm{mg} / \mathrm{kg}$ and $2000 \mathrm{mg} / \mathrm{kg}$ body weight.

\subsection{Experimental Protocol}

2.4.1. Investigation 1: Effect of Various Doses of M. madrespatana to Assess the Exploratory Activity in the Novel and Familiar Environment to Find Out the Potential Dose

Thirty animals were housed individually and divided into six groups each $(n=5)$. Various doses of M. madrespatana fruit peel powder ranging from 0.0, 125.0, 250.0, 500.0, 1000.0, and $2000.0 \mathrm{mg} / \mathrm{kg} / \mathrm{day}$ were orally given to each group at 9:00-10:00 a.m. for 28 days. During this time, the health of the animals was monitored. After four weeks of the home cage (familiar environment) and open field (novel environment), activity was performed for 5 min each.

2.4.2. Investigation 2: Effect of Potential/Selected Dose (2000 mg/kg/day) of M. madrespatana on Behavioral Deficits, Oxidative Stress, and Memory Function Induced by Single Immobilization Stress

20 rats separated into two groups $(n=10)$. (i) Control group and (ii) test group. The control group received drinking water while the test group was given $2000 \mathrm{mg} / \mathrm{kg} /$ day of M.M. fruit peel powder orally (at 10:00-11:00 a.m.) for four weeks. On day 29, both groups were further divided into four groups $(n=5)$ (i) Unstressed + water (ii) Stressed + Water (iii) Unstressed + M.M (iv) Stressed + M.M. Number of animals in sub-groups used in the present study was already reported [28]. Animals of the stressed groups were immobilized on metal wire grids for $2 \mathrm{~h}$ (at 7:00-9:00 am) in a separate room. Meanwhile, unstressed groups were left in their home cages. For $24 \mathrm{~h}$ post-immobilization stress (on day 30), behavioral activities include: (i) an elevated plus maze (EPM) test, (ii) light/dark activity (LDA) test, (iii) forced swim test (FST), and (iv) Morris water maze (MWM) test (acquisition and short term memory) were conducted between 9:00 a.m. to 6:00 p.m. with the help of blind observers. On day 31, long-term memory of all animals was assessed using MWM. After that, animals were decapitated 
and the hippocampi (brain region) were removed [29], kept frozen at $-20{ }^{\circ} \mathrm{C}$, and utilized for further biochemical analysis $24 \mathrm{~h}$ after the decapitation.

\subsubsection{Immobilization Stress Procedure}

The animals were immobilized on wire grids of $10^{\prime \prime} \times 9^{\prime \prime}$ fitted with a Perspex plate of $9^{\prime \prime} \times 6.5^{\prime \prime}$. The previously described procedure was used for the immobilization of animals [30]. Immobilization was produced by pressing the forelegs of the rat through the gaps in the metal grids and taping them together with Zinc Oxide plaster tape. Hind limbs were also taped and the head of the animal rested on the Perspex plate. Unstressed groups were kept in their home cages during the immobilization period.

\subsection{Behavioral Tests}

\subsubsection{Elevated Plus Maze (EPM) Test}

Elevated plus-maze is used for the measurement of anxiolytic activity of test compounds and, for the said purpose we used, the apparatus of plus shape with the total dimensions of $110 \times 10 \times 15 \mathrm{~cm}$. The closed and open arms are distinguished with the central $10 \mathrm{~cm}$ arena. For the testing purpose, we used the protocol established previously [31]. The animal was permitted to visit on the elevated stage for $5 \mathrm{~min}$ and behavioral assessment was done by its time and frequency spent in open arm vs. closed arm. The top-mounted camera system (Logitech C-310, Basel, Switzerland) recorded the videos. Between each trial, the apparatus was cleaned with $70 \%$ isopropyl alcohol to wash out the smell of the previous trial.

\subsubsection{Light-Dark Activity (LDA) Test}

A customized-made apparatus of acrylic glass was used for measuring an animal's anxiety behavior in a two compartmental system of light and dark environment. The dimension of the apparatus is $40 \times 30 \times 35 \mathrm{~cm}$ where light and dark compartments are equally divided, i.e., $20 \mathrm{~cm}$ each and central door of $10 \times 10 \mathrm{~cm}$ allows free passage of animals between the compartments. The total duration of the test is $5 \mathrm{~min}$ in which the duration of the animal's time spent in each compartment was noted with the lateral camera recording system. Subsequently, the recorded videos were analyzed by a blinded observer to the experiments with the help of a stopwatch.

\subsubsection{Forced Swim Test (FST)}

The forced swim test (FST) has a widely employed method for evaluating the depressant/antidepressant behavior of rodents [31]. In the experiment, we used a glass tank with a dimension of $45 \mathrm{~cm}$ in height and $30 \mathrm{~cm}$ in the radius for assessing the antidepressant activity of the test substances. The apparatus was full of water $\left(25^{\circ} \mathrm{C}\right)$ up to $\sim 35 \mathrm{~cm}$ where the feet of the animal should not get the support from the basement and become, simultaneously, inescapable from the tank [28]. In a trial session of $15 \mathrm{~min}$ each, all animals were allowed to force swim. In an experimental session, $24 \mathrm{~h}$ after the trial session, the treated rats were challenged to the environment of inescapability and difference between the states of mobility (climbing and swimming) vs. immobility was observed by lateral recording, which was, subsequently, analyzed by a blinded observer. The rat will be considered in a phase of depression where it spent most of the time in a phase of immobility and makes virtually no efforts to escape and merely attempt to retain its head above the water.

\subsubsection{Morris Water Maze (MWM) Test}

In this test, we assessed the impact of M.M. fruit peel powder on the retention of spatial memory in rats. For the purpose, we used a customized circular tank of grey color with a dimension of $150 \mathrm{~cm}$ in radius and $50 \mathrm{~cm}$ in height [32]. The tank was filled with water and the temperature was maintained at $25{ }^{\circ} \mathrm{C}$ throughout the experiment. The tank was equally divided into quadrants, i.e., north-east (NE), south-east (SE), (north-west (NW), and south-west (SW), and an opaque color platform made of acrylic 
glass was placed in the SW quadrant of the tank. The distal cues with distinct shapes were placed in all four quadrants of tank walls, which were helpful for the animal to navigate in the tank and direction. Before starting the experiment, the color of the water was changed to murky with the addition of nonhazardous white ink and the platform was submerged $1-2 \mathrm{~cm}$ in water. The test was performed in two sessions: (1) the training session and (2) test phases, which is comprised of retention of short (1 h after training) and long (24 h after training) term retention of memory [33]. The animal was placed all the time from the same quadrant, i.e., NE and headed for the wall of the tank. In the training phase, each rat was allowed 2 min time to navigate and find the hidden platform and, if located within the cut-off time, the animal was permissible to stay at the platform for 10-20 s to navigate the surroundings. Otherwise, after $2 \mathrm{~min}$, the animal was directed to the platform by manually guiding it to the platform. One hour after the training phase, short-term retention of memory was performed on the trained rats, and latency to reach the platform was noted. The videos were recorded on the top-mounted camera and, subsequently, analyzed by Any-Maze (V 6.01) video tracking software (Wood Dale, IL, USA).

\subsection{Biochemical Analysis}

Decapitation of all animals was done on the same day after behavioral tests. Brain samples were detached and the hippocampus was removed, weighed (averagely $76 \mathrm{mg}$ ), and washed with $0.9 \%$ saline solution and used for various biochemical tests $24 \mathrm{~h}$ after the decapitation. A tissue homogenate $10 \%$ (wt./vol.) was prepared with phosphate buffer $(0.1 \mathrm{M}, \mathrm{pH} 7.4)$ and got by centrifugation $(12,000 \times g)$ for $20 \mathrm{~min}$ at $4{ }^{\circ} \mathrm{C}$ for all biochemical estimations.

\subsubsection{Determination of Malondialdehyde (MDA)}

The method of Chow \& Tappel [34] was used for the analysis of malondialdehyde with some changes in the procedure. $0.3 \mu \mathrm{L}$ hippocampus homogenate was added in a $2 \mathrm{~mL}$ trichloro-acetic acid-thio-barbituric acid (TCA-TBA) solution and then boiled in a water bath for $20 \mathrm{~min}$. The mixture was then cooled down and centrifuged (35,000 RPM) for $10 \mathrm{~min}$. Light pink-colored supernatant was collected and $532 \mathrm{~nm}$ absorbance was used to note the absorbance.

\subsubsection{Determination of Superoxide Dismutase (SOD) Activity}

The previously reported method was used for the analysis of SOD [35]. A total of $300 \mu \mathrm{L}$ of hippocampus homogenate was centrifuged with $0.75 \mathrm{~mL}$ ethanol and $0.15 \mathrm{~mL}$ of chloroform. After centrifugation, $500 \mu \mathrm{L}$ supernatant was taken and then $0.5 \mathrm{~mL}$ EDTA and $1.0 \mathrm{~mL}$ of $0.1 \mathrm{M}$ carbonate-bicarbonate buffer ( $\mathrm{pH}$ 10.2) were added. By adding $0.5 \mathrm{~mL}$ of an epinephrine reaction, absorbance was taken at $480 \mathrm{~nm}$, and the percentage inhibition of SOD was calculated.

\subsubsection{Determination of Catalase (CAT) Activity}

A total of $100 \mu \mathrm{L}$ hippocampus supernatants mixed with $1.4 \mathrm{~mL}$ solution comprised of $400 \mu \mathrm{L}$ of hydrogen peroxide and $1 \mathrm{~mL}$ of phosphate buffer $(0.01 \mathrm{M}, \mathrm{pH} 7.0)$. The reaction was stopped $1 \mathrm{~min}$ after by adding $2 \mathrm{~mL}$ of the reagent (dichromate acetic acid). To calculate the activity of CAT, absorbance was taken at $620 \mathrm{~nm}$, as described previously [36].

\subsubsection{Determination of Glutathione Peroxidase (GPx) Activity}

The method of Flohe \& Gunzler [37] was used to measure the activity of GPx as $\mu \mathrm{mol} / \mathrm{min} / \mathrm{g}$ of the hippocampus. A total of $1.0 \mathrm{~mL}$ of reaction solution that contained $0.3 \mathrm{~mL}$ phosphate buffer $(0.1 \mathrm{M}, \mathrm{pH}$ 7.4), $0.2 \mathrm{~mL}$ of glutathione reduced, $0.1 \mathrm{~mL}$ of sodium azide, $0.1 \mathrm{~mL}$ of hydrogen peroxide, and $0.3 \mathrm{~mL}$ of homogenate was prepared. The reaction solution was incubated for $15 \mathrm{~min}$ at $37^{\circ} \mathrm{C}$ by adding $0.5 \mathrm{~mL}$ of TCA. The reaction was terminated and the solution was centrifuged $(1500 \times \mathrm{g})$ for $15 \mathrm{~min}$ and filtrate was removed. A total of $0.2 \mathrm{~mL}$ phosphate buffer and $0.7 \mathrm{~mL} 5,5^{\prime}$-dithiobis-(2-nitrobenzoic acid (DTNB) were mixed with $0.1 \mathrm{~mL}$ of filtrate. The absorbance of the solution was recorded at $420 \mathrm{~nm}$. 


\subsubsection{Determination of Acetylcholinesterase (AChE) Activity}

The method of Ellman et al. [38] was used to estimate the activity of AChE. A total of $0.4 \mathrm{~mL}$ hippocampus homogenate, $2.6 \mathrm{~mL}$ phosphate buffer, and $0.1 \mathrm{~mL}$ DTNB were mixed by bubbling air and put down into a spectrophotometer. When the reaction solution was steady, the basal reading followed by the addition of $5.2 \mu \mathrm{L}$ of acetylthiocholine iodide in a cuvette contained a reaction solution. Absorbance was recorded at $412 \mathrm{~nm}$. The activity of AChE was mentioned as $\mu \mathrm{mol} / \mathrm{min} / \mathrm{g}$ of tissue.

\subsubsection{Determination of 5-HT and 5-HIAA}

5-hydroxy indole acetic acid (5-HIAA) and 5-hydroxytryptamine (5-HT) levels in the hippocampus were estimated using the method described by Samad et al. [28]. Reversed-phase High-Performance Liquid Chromatography (HPLC) with an electrochemical detector (Shimadzu LEC 6A detector) was performed to detect levels of biogenic amines in brain samples. The electro-chemical (EC) detector was operated at a potential of $+0.8 \mathrm{~V}$. The stationary phase used for separation is a $5-\mu$ Shim-pack octa-decyl silane (ODS) column having an internal diameter of $4.0 \mathrm{~mm}$ and a length of $150 \mathrm{~mm}$. The mobile phase that passes through a column with a pump pressure of 2000-3000 psi contains octyl sodium sulfate $(0.023 \%)$ in $0.1 \mathrm{M}$ phosphate buffer at $\mathrm{pH} 2.9$.

\subsubsection{Determination of Acetylcholine (ACh)}

The level of ACh concentration was determined as described by Reference [39] and was presented as $\mu \mathrm{mol} / \mathrm{g}$ of the hippocampus. The tissue sample was boiled to release the bound ACh and inactivate the enzyme. The reaction mixture was then mixed with ferric chloride $1 \%(1000 \mu \mathrm{L})$ to form a brown color complex and read at $540 \mathrm{~nm}$ against the reagent blank.

\subsection{Statistical Analysis}

Data of exploratory activity in the novel and familiar environment were analyzed by One-Way ANOVA. All the biochemical and behavioral (Post stress) data were analyzed by Tukey's test and this was followed by two-way ANOVA. All the data analyzed by SPSS ver. 20.0 (IBM, Chicago, IL, USA). $p<0.05$ was taken as significant.

\section{Results}

\subsection{Various Doses of M. madrespatana Peel}

Effect of M. madrespatana doses on exploratory activities in an open field and home cage shown in Figure 1. Data on activity in an open field test was evaluated by one-way ANOVA $(\mathrm{df}=5.24)$ ( $\mathrm{F}=87.45, p=0.001$ ), which showed a substantial effect of M. madrespatana. Activity of M. madrespatana at doses $0.0,125.0,250.0,500.0,1000.0$, and $2000.0 \mathrm{mg} / \mathrm{kg} /$ day substantially increased when evaluated by Tukey's test.

Data on activity in the home cage was analyzed by one-way ANOVA $(\mathrm{df}=5.24)(\mathrm{F}=50.72$, $p=0.001$ ) showed substantial effect. M. madrespatana at doses 0.0, 125.0, 250.0, 500.0, 1000.0, and $2000.0 \mathrm{mg} / \mathrm{kg} /$ day substantially increased when evaluated by Tukey's test. 

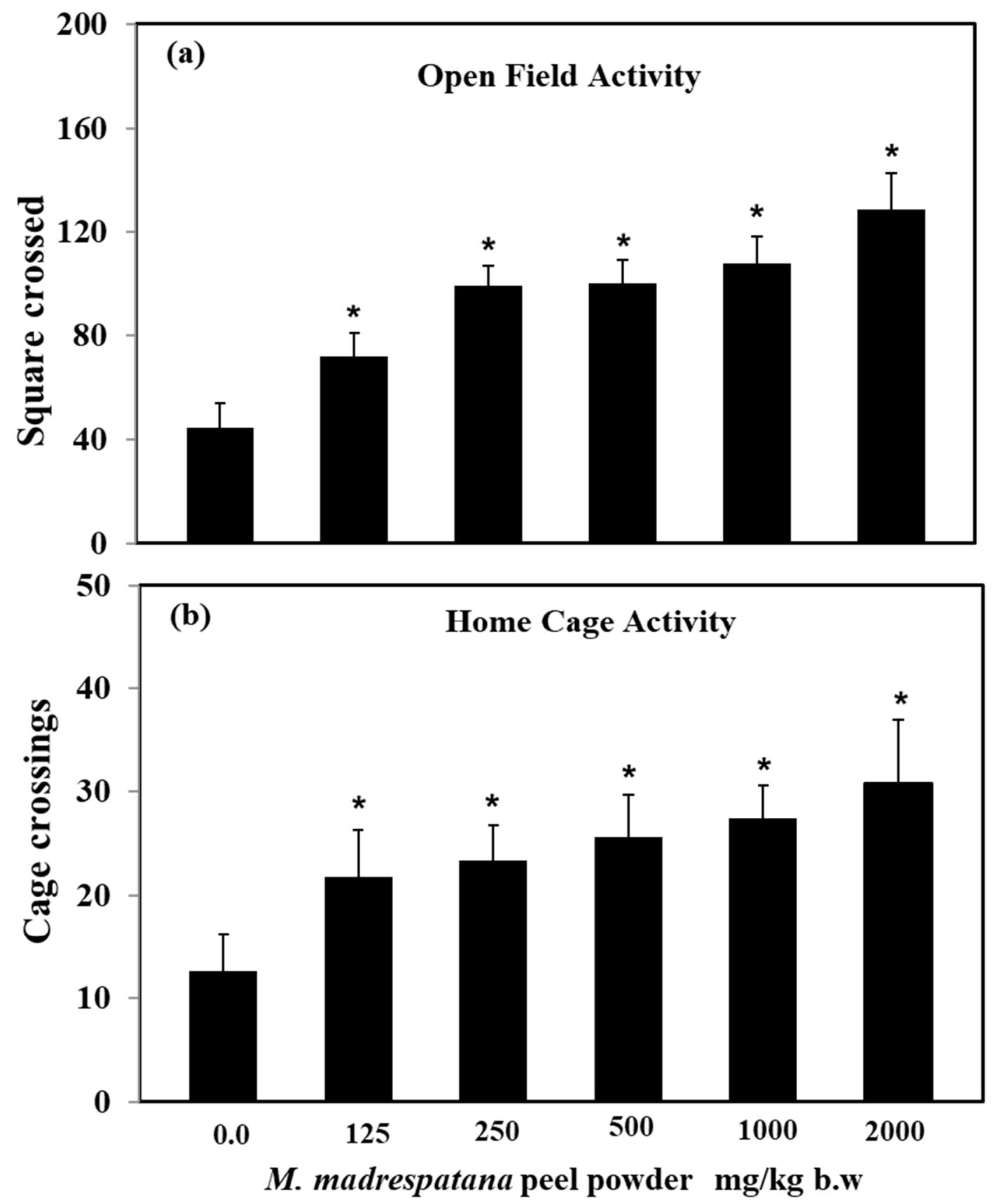

Figure 1. Effects of M. madrespatana with various doses in a novel (a) and familiar (b) environment. Values are means \pm standard deviation $(n=5) 4$ weeks after the administration of the drug. Significant differences by Tukey's test * $p<0.05$ from control animals following one-way ANOVA.

\subsection{Elevated Plus-Maze (EPM)}

Figure 2 shows the effect of M. madrespatana on anxiety-like symptoms tested via EPM. Data evaluated by two-way ANOVA $(\mathrm{df}=1.16)$ showed the substantial effects of stress $(\mathrm{F}=26.192, p=0.001)$, M. madrespatana $(\mathrm{F}=118.678, p=0.0001)$, and interaction between stress $\times$ M. madrespatana. $(\mathrm{F}=8.966$, $p=0.001)$. Tukey's test exhibited that single stress lessened time spent in an open arm. Time spent in open arms markedly enhanced in M. madrespatana treated (unstressed and stressed) than their respective control. 


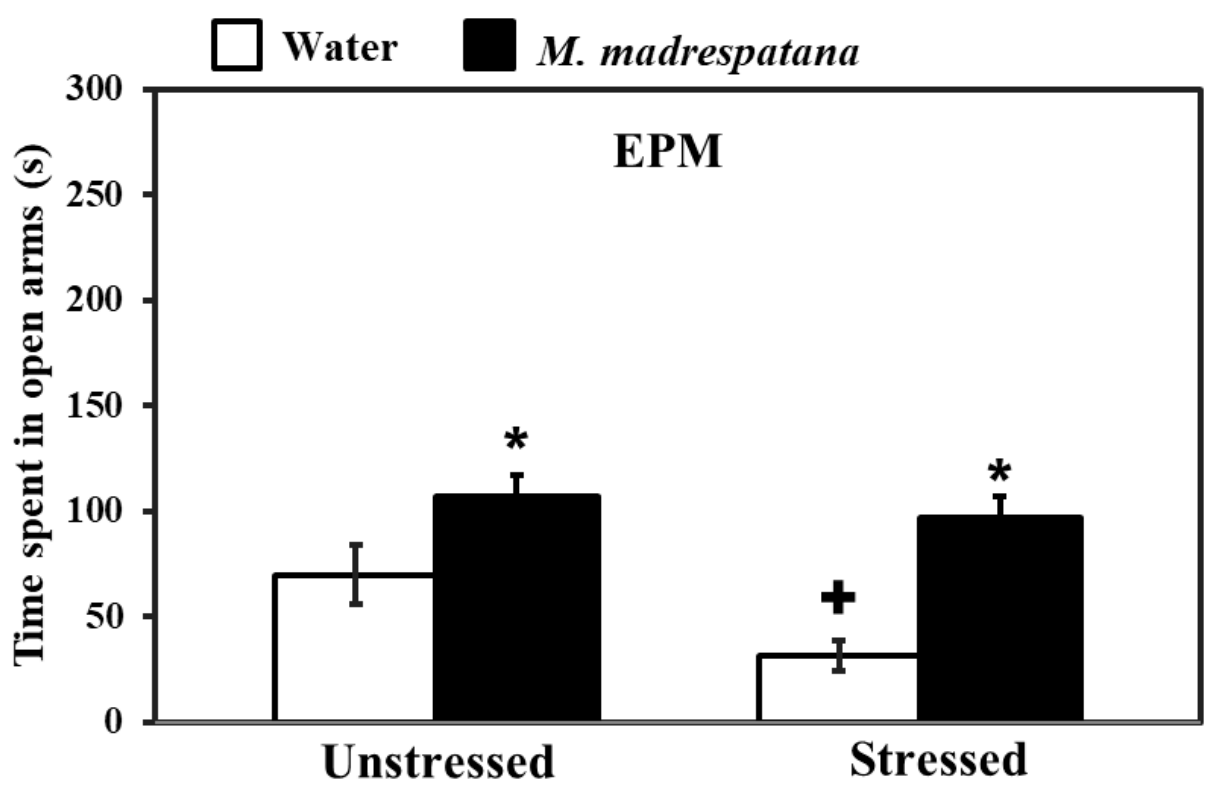

Figure 2. Effects of administration of M. madrespatana on the anxiety profile in unstressed and stressed rats observed in EPM. Values are mean \pm standard deviation $(n=5)$. Data were analyzed by Tukey's test following two-way ANOVA. Statistical difference is expressed as $* p<0.05$ versus respective control and $+p<0.05$ versus unstressed rats.

\subsection{Light/Dark Box Activity}

Figure 3 shows the effect of $M$. madrespatana on anxiety-like behavior tested via the light/dark box. Data evaluated by two-way ANOVA $(\mathrm{df}=1.16)$ showed the substantial effects of stress $(\mathrm{F}=105.527$, $p=0.0001), M$. madrespatana $(\mathrm{F}=181.696, p=0.0001)$, and interaction between stress $\times M$. madrespatana $(\mathrm{F}=42.541, p=0.002)$. Tukey's test exhibited that acute stress lessened time spent in the lightbox. Time spent in the lightbox substantially enhanced treated unstressed and stressed animals in M. madrespatana than their counterparts.

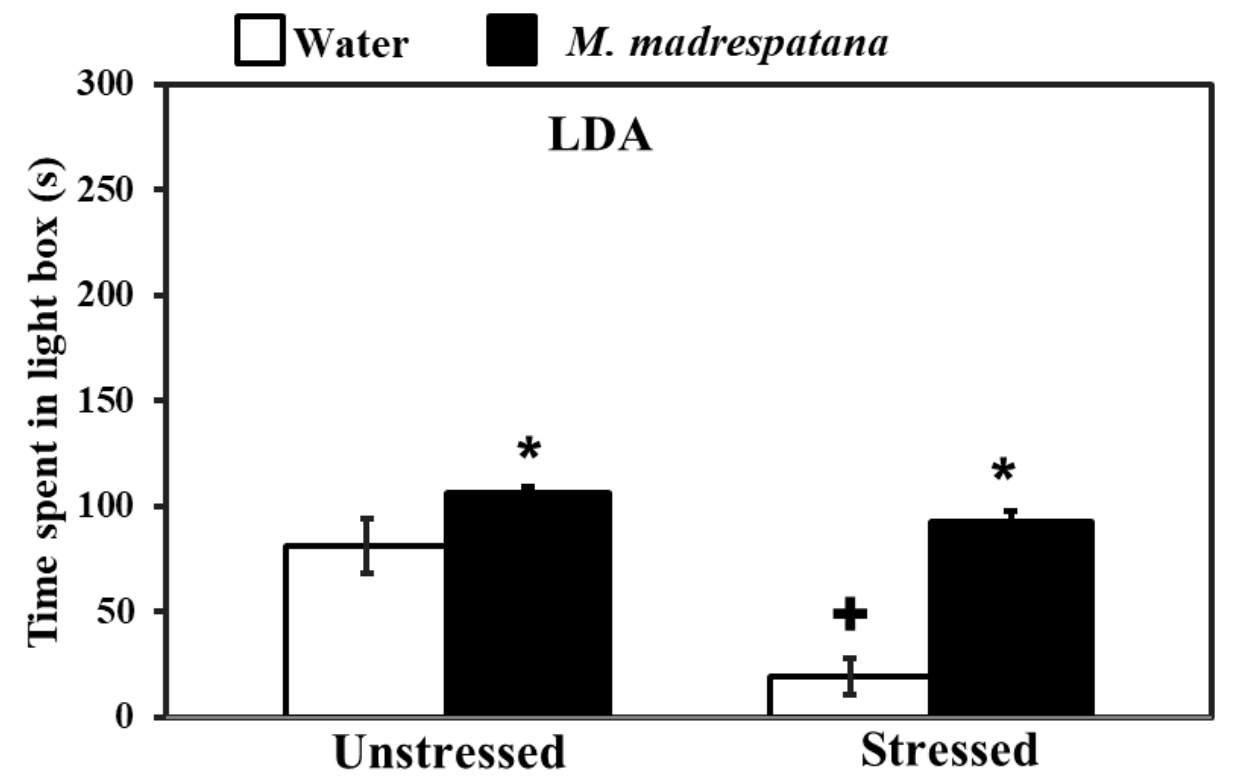

Figure 3. Effects of administration of M.M. on anxiety profile in unstressed and stressed rats observed in the light-dark activity box. Values are mean \pm standard deviation $(n=5)$. Data were analyzed by Tukey's test following two-way ANOVA. Statistical difference is expressed as ${ }^{*} p<0.05$ versus respective control and $+p<0.05$ versus unstressed rats. 


\subsection{Forced Swim Test (FST)}

Figure 4 shows the effects of M. madrespatana on depression-like symptoms tested through FST. Data evaluated by two-way ANOVA $(\mathrm{df}=1.16)$ showed the substantial effects of stress $(\mathrm{F}=72.129$, $p=0.001), M$. madrespatana $(\mathrm{F}=329.089, p=0.0001)$, and stress $\times$ M. madrespatana $(\mathrm{F}=45.244, p=0.001)$ on immobility time. Tukey's test exhibited that immobilization substantially enhanced immobility time in water-treated rats. Immobility time substantially reduced in M. madrespatana-treated unstressed and stressed animals than their counterparts.
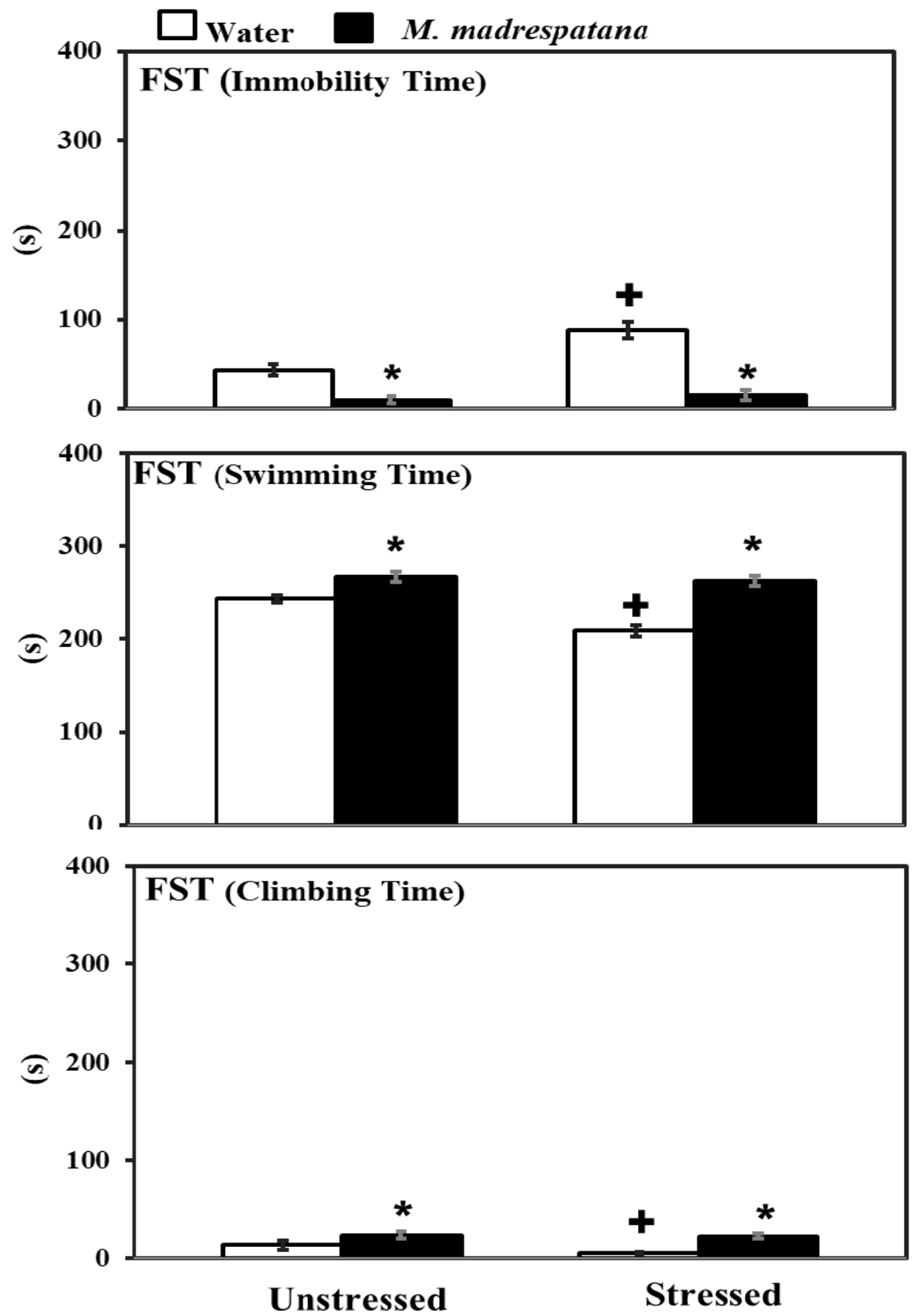

Figure 4. Effects of M. madrespatana administration following immobilization stress on immobility, swimming, and climbing time in FST. Values are mean \pm standard deviation $(n=5)$. Data were analyzed by Tukey's test following two-way ANOVA. Statistical difference is expressed as ${ }^{*} p<0.05$ versus respective control and $+p<0.05$ versus unstressed rats. 
Data evaluated by two-way ANOVA $(\mathrm{df}=1.16)$ showed the substantial effects of stress $(\mathrm{F}=59.03$, $p=0.001), M$. madrespatana $(\mathrm{F}=233.71, P=0.0001)$, and stress $\times$ M. madrespatana $(\mathrm{F}=34.35, p=0.001)$ on swimming time. Tukey's test exhibited that immobilization substantially reduced swimming time in water-treated rats. Swimming time substantially enhanced in M. madrespatana treated unstressed and stressed animals than their counterparts.

Data evaluated by two-way ANOVA $(\mathrm{df}=1.16)$ showed the substantial effects of stress $(\mathrm{F}=8.78$, $p=0.009), M$. madrespatana $(\mathrm{F}=83.88, p=0.0001)$, and stress $\times M$. madrespatana $(\mathrm{F}=4.64, p=0.04)$ on climbing time. Tukey's test exhibited that immobilization substantially reduced climbing time in water-treated rats. Climbing time substantially enhanced in M. madrespatana treated unstressed and stressed animals than their counterparts.

\subsection{Morris Water Maze (MWM) Test}

Figure 5 shows the effect of M. madrespatana on memory tests via the Morris water maze. All the data evaluated by two-way ANOVA $(\mathrm{df}=1.16)$. Data of acquisition (5a) exhibited that effect of stress $(\mathrm{F}=2.092, p=0.11), M$. madrespatana $(\mathrm{F}=3.329, p=0.14)$, and stress $\times$ M. madrespatana $(\mathrm{F}=0.087$, $p=0.21)$ was non-substantial.
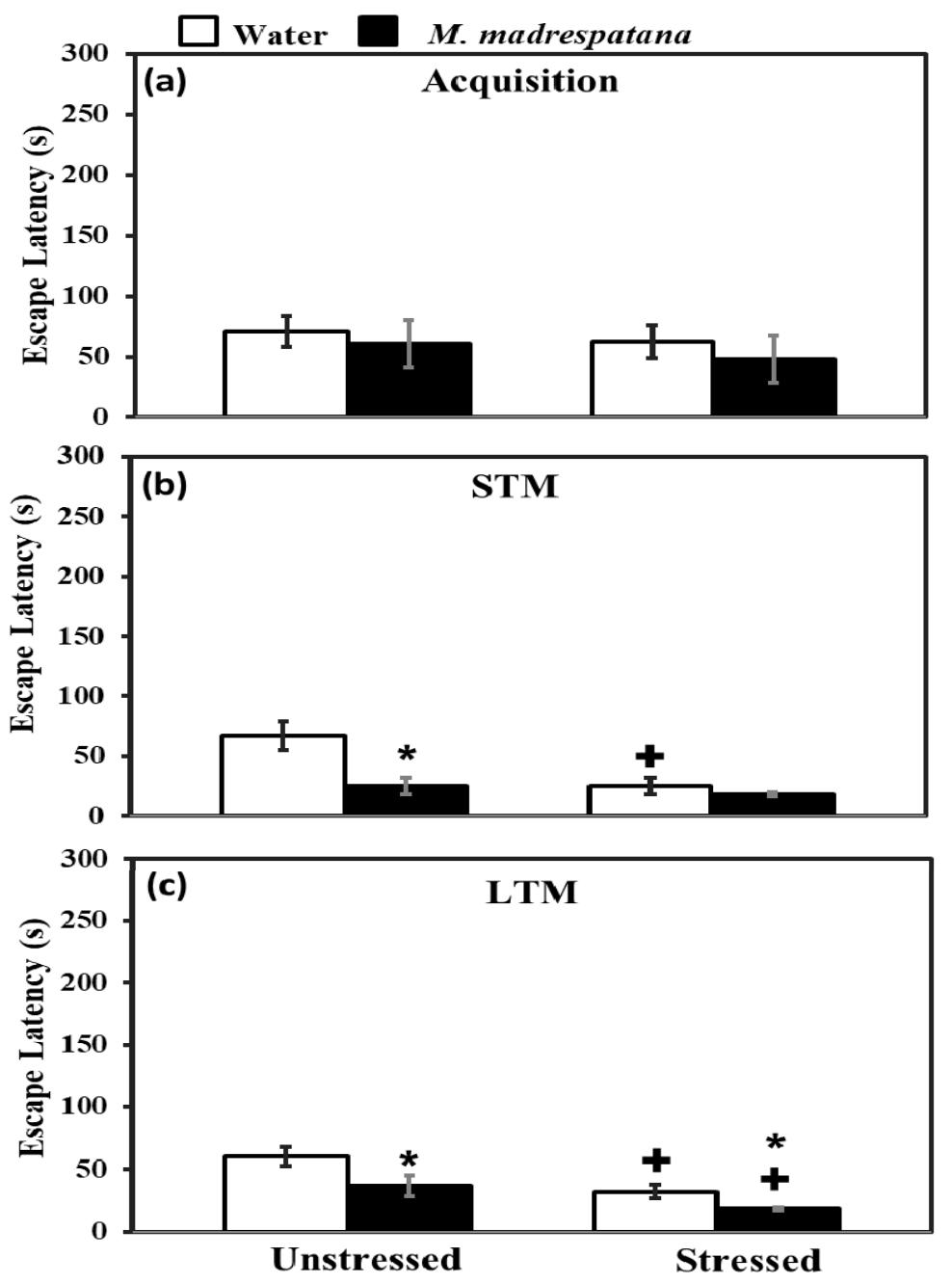

Figure 5. Effect of M. madrespatana administration following single stress on acquisition (a) STM (b) and LTM (c) in terms of escape latency (s) assessed by MWM. Values are mean \pm standard deviation $(n=5)$. Data were analyzed by Tukey's test following two-way ANOVA. Statistical difference is expressed as ${ }^{*} p<0.05$ versus respective control and $+p<0.05$ versus unstressed animals. 
Data on short term memory (STM) (5b) exhibited a substantial effect of stress $(\mathrm{F}=14.381, p=0.005)$, M. madrespatana $(\mathrm{F}=128.833, p=0.0001)$, and stress $\times$ M. madrespatana $(\mathrm{F}=58.285, p=0.001)$. Tukey's test exhibited a considerable decrease in escape latency in M.M. treated unstressed and control stressed groups than their respective control group.

Data on long-term memory (LTM) (5c) exhibited a substantial effect of stress (F = 69.992, $p=0.0001)$ and M. madrespatana $(\mathrm{F}=44.026, p=0.001)$ while stress $\times$ M. madrespatana interaction $(\mathrm{F}=2.818, p=0.02)$ was non-substantial. Tukey's test showed a considerable decrease in escape latency of $M$. madrespatana-treated unstressed and stressed groups than their counterparts. Single immobilization stress also lessened escape latency in water-treated animals. Escape latency was smaller in M. madrespatana-treated stressed animals than unstressed animals.

\subsection{Assessment of Oxidative Stress}

Figure 6 shows the effect of M. madrespatana on malondialdehyde (MDA) content of the hippocampus in unstressed and stressed animals. Data evaluated by two-way ANOVA $(\mathrm{df}=1.16)$ showed substantial effects of $M$. madrespatana $(\mathrm{F}=116.12, p=0.001)$, stress $(\mathrm{F}=8.25, p=0.03)$, and stress $\times$ M. madrespatana $(\mathrm{F}=33.03, p=0.004)$. Tukey's test exhibited that the contents of MDA markedly increased following immobilization in water-treated animals. The contents of MDA reduced in M. madrespatana-treated unstressed and stressed rats than their respective control.

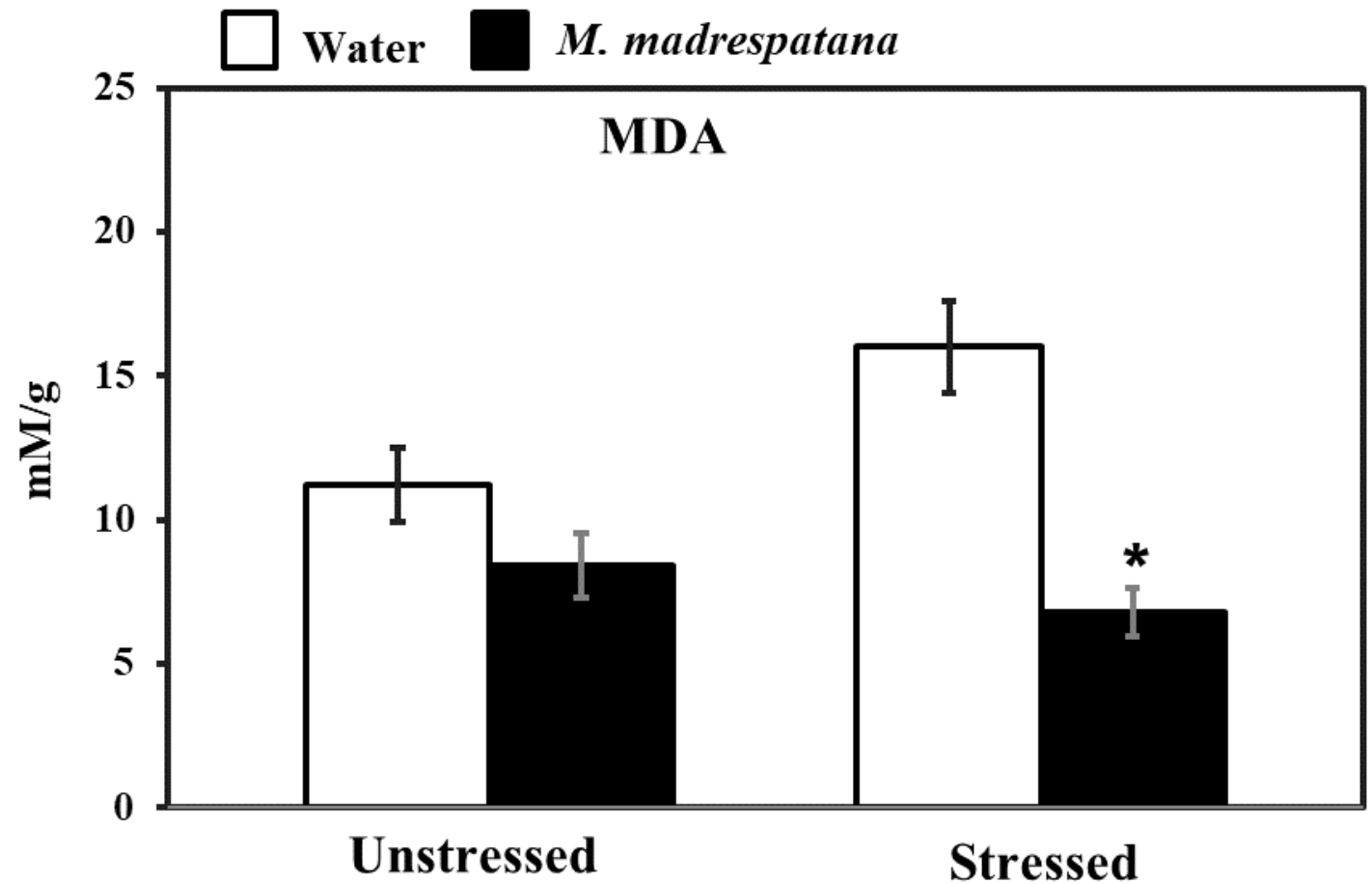

Figure 6. Effects of M. madrespatana administration following immobilization stress on hippocampal MDA activity. Values are mean \pm standard deviation $(n=5)$. Data were analyzed by Tukey's test following two-way ANOVA. Statistical difference is expressed as ${ }^{*} p<0.05$ versus respective control and $+p<0.05$ versus unstressed animals.

\subsection{Determination of Antioxidant Enzymes}

Figure 7 shows the effect of M. madrespatana on antioxidant enzyme levels in the hippocampus of unstressed and stressed animals. All the data evaluated by two-way ANOVA $(\mathrm{df}=1.16)$. Data on SOD exhibited a substantial effect of stress $(\mathrm{F}=14.381, p=0.01)$, M. madrespatana $(\mathrm{F}=128.833, p=0.001)$, and stress $\times$ M. madrespatana $(\mathrm{F}=58.285, p=0.0004)$. Tukey's test exhibited that the activity of SOD in 
the hippocampus increased in M.M treated unstressed and stressed rats than their counterparts. SOD levels lessened in water + stressed than water + unstressed group.
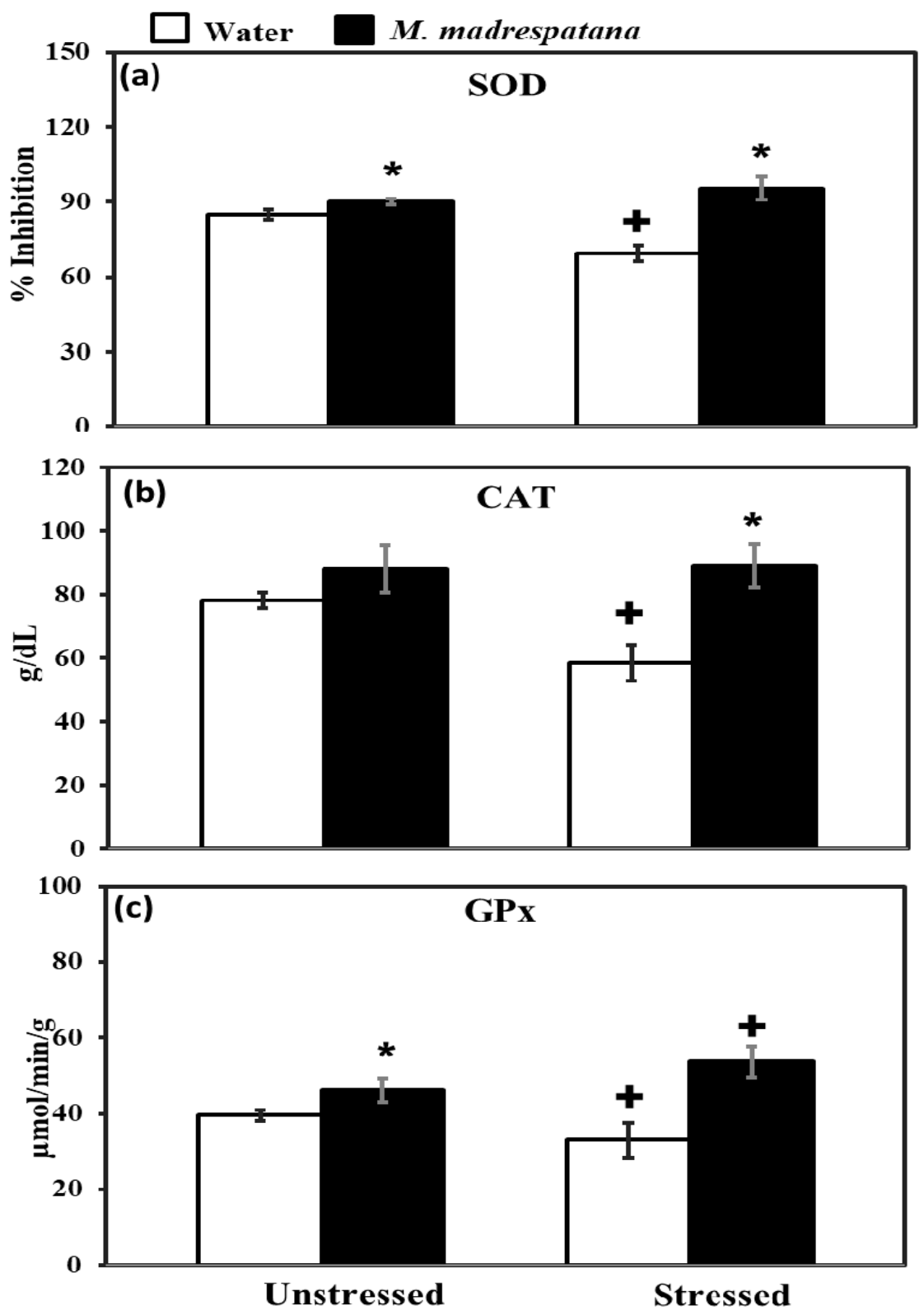

Figure 7. Effect of $M$. madrespatana administration following immobilization stress on hippocampal SOD (a), CAT (b), and GPx (c) activity. Values are mean \pm standard deviation $(n=5)$. Data was analyzed by Tukey's test following two-way ANOVA. Statistical difference is expressed as * $p<0.05$ versus respective control and $+p<0.05$ versus unstressed rats.

Data on CAT showed a substantial effect of stress $(\mathrm{F}=12.18, p=0.005)$, M. madrespatana $(\mathrm{F}=56.95$, $p=0.002)$, and stress $\times M$. madrespatana $(\mathrm{F}=15.01, p=0.01)$. Tukey's test exhibited that CAT activity in the hippocampus was decreased in control stress. The activity of CAT was enhanced in M. madrespatana-treated stressed animals than water-treated stressed animals.

Data on GPx activity showed substantial effects of M. madrespatana $(\mathrm{F}=75.985, p=0.0001)$ and interaction of stress $\times M$. madrespatana $(\mathrm{F}=20.104, p=0.001)$ while the effect of stress $(\mathrm{F}=0.106$, $p=0.13$ ) was non-substantial. Tukey's test showed GPx activity in the hippocampus increased M. madrespatana-treated unstressed and stressed versus their counterparts. On the other hand, single stress lessened GPx activity in water-treated animals. 


\subsection{Determination of $A C h E$}

Figure 8 shows the effect of M. madrespatana on hippocampal AChE activity in unstressed and stressed animals. Data evaluated by two-way ANOVA exhibited a substantial effect of stress $(\mathrm{F}=21.482, p=0.0003)$, M. madrespatana $(\mathrm{F}=34.962, p=0.0001)$, and stress $\times$ M. madrespatana $(\mathrm{F}=1.706$, $p=0.01)$. Tukey's test exhibited single stress lessened AChE activity in control animals. The activity of AChE significantly lessened in M. madrespatana-treated unstressed rats and stressed rats than their respective control.

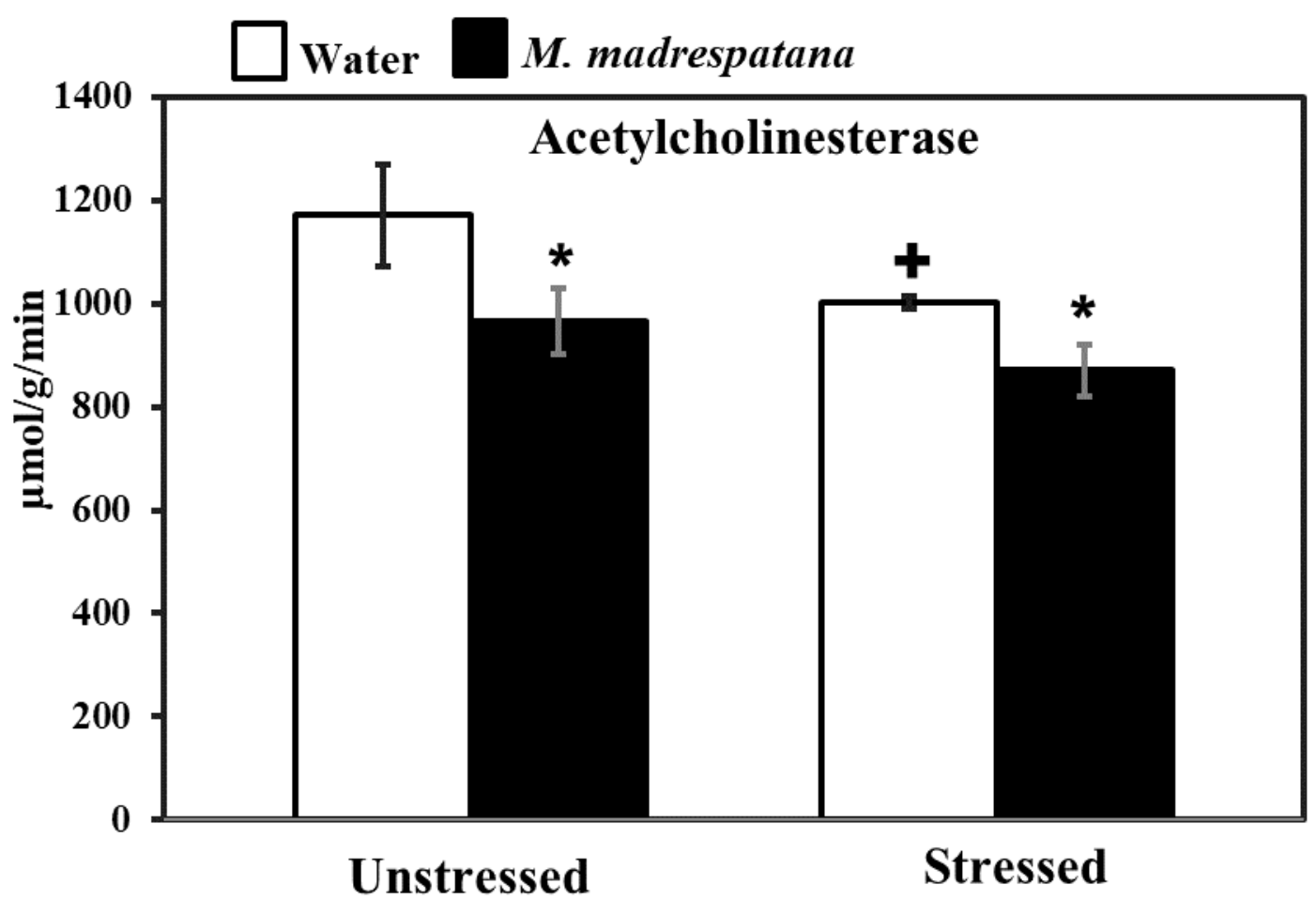

Figure 8. Effects of M.M. administration following immobilization stress on AChE activity in the hippocampus. Values are mean \pm standard deviation $(n=5)$. Data were analyzed by Tukey's test following two-way ANOVA. Statistical difference is expressed as $* p<0.05$ versus respective control and $+p<0.05$ versus unstressed animals.

\subsection{Determination of 5-Hydroxy Tryptamine (5-HT) and 5-Hydroxy Indole Acetic Acid (5-HIAA) Levels}

Figure 9 shows the effect of M. madrespatana on 5-HT and 5-HIAA levels of the hippocampus in unstressed and stressed rats. All the data evaluated by two-way ANOVA ( $\mathrm{df}=1.16)$. Data on 5-HT levels exhibited a substantial effect of stress $(\mathrm{F}=188.855, p=0.0001)$, M. madrespatana $(\mathrm{F}=123.386$, $p=0.0001)$ stress $\times$ M. madrespatana $(\mathrm{F}=77.935, p=0.002)$. Tukey's test showed that 5-HT levels of the hippocampus significantly enhanced in control stressed subjects than unstressed subjects. The levels of 5-HT in the hippocampus decreased in M. madrespatana-treated stressed animals than their respective control. While in $M$. madrespatana-treated stressed animals, levels of 5-HT were greater than M. madrespatana-treated unstressed rats.

Data on 5-HIAA levels exhibited a substantial effect of stress $(\mathrm{F}=455.027, p=0.0001)$, M. madrespatana $(\mathrm{F}=556.172, p=0.0001)$, and interaction between stress $\times$ M. madrespatana $(\mathrm{F}=200.325$, $p=0.0003)$. Tukey's test showed that single stress increased 5-HIAA levels of the hippocampus in water-treated animals. The levels of 5-HIAA decreased in both M. madrespatana-treated unstressed and stressed animals. The levels of 5-HIAA greater in M. madrespatana-treated stressed than unstressed animals. 

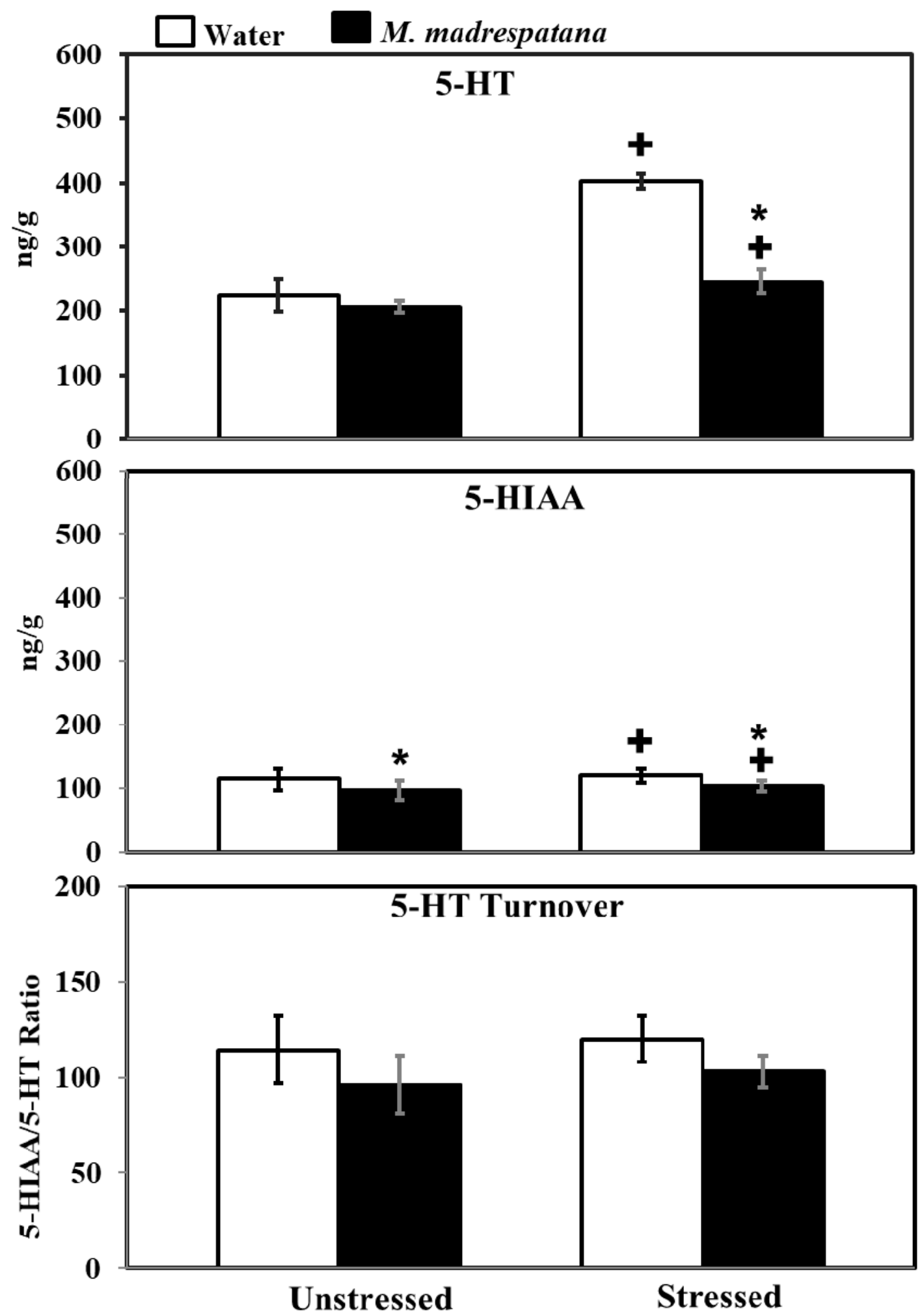

Figure 9. Effect of M. madrespatana administration following immobilization stress on 5-HT, 5-HIAA levels, and 5-HT turnover in terms of 5-HIAA/5-HT ratio in the hippocampus. Values are mean \pm standard deviation $(n=5)$. Data were analyzed by Tukey's test following two-way ANOVA. Statistical difference is expressed as * $p<0.05$ versus respective control and $+p<0.05$ versus unstressed animals. 
Data on 5-HIAA/5-HT ratio exhibited a substantial effect of $M$. madrespatana $(\mathrm{F}=12.32, p=0.003)$, while non-substantial stress $(\mathrm{F}=1.525, p=0.235)$ and interaction between stress $\times M$. madrespatana $(\mathrm{F}=0.023, p=0.881)$. Tukey's test showed non-substantial effects.

\subsection{Determination of ACh Levels}

Figure 10 displays the effect of M. madrespatana on ACh levels of the hippocampus in unstressed and stressed rats. All the data evaluated by two-way ANOVA ( $\mathrm{df}=1.16)$. Data on ACh levels exhibited a substantial effect of $M$. madrespatana $(\mathrm{F}=61.12, p=0.0001)$, stress $\times$ M. madrespatana $(\mathrm{F}=55.97$, $p=0.0001)$, while the effect of stress $(\mathrm{F}=0.17, p=0.680)$ was not substantial. Tukey's test showed that ACh levels of the hippocampus significantly increased in the stressed control than the unstressed sample. The levels of ACh in the hippocampus increased in M. madrespatana-treated unstressed and stressed rats than their respective control.

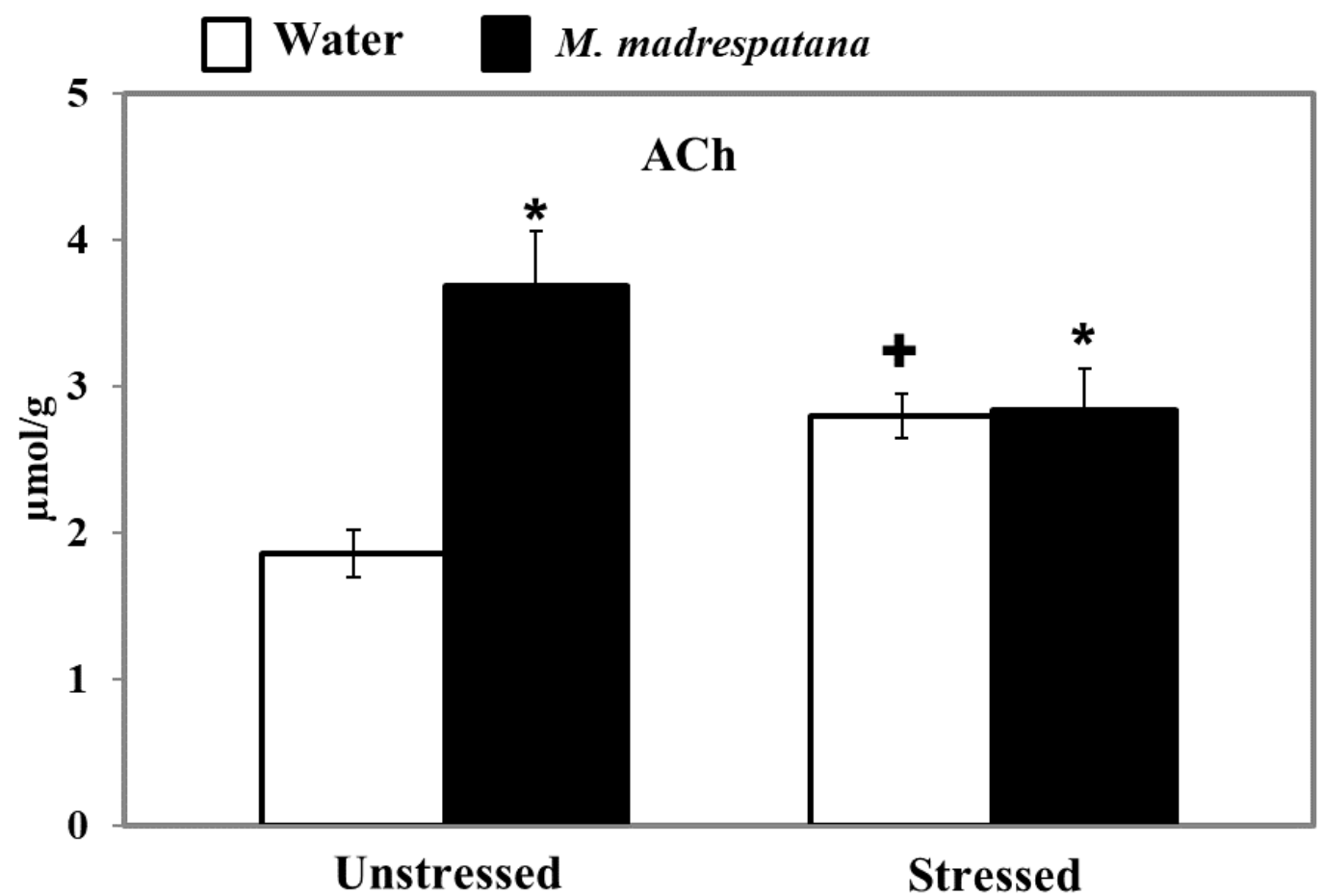

Figure 10. Effect of M. madrespatana administration following immobilization stress on ACh levels in the hippocampus. Values are mean $\pm \mathrm{SD}(n=5)$. Data were analyzed by Tukey's test following two-way ANOVA. Statistical difference is expressed as ${ }^{*} p<0.05$ versus respective control and $+p<0.05$ versus unstressed animals.

\section{Discussion}

The present study aimed to investigate the effect of repeated administration of $M$. madrespatana fruit peel powder on single immobilization-induced behavioral and biochemical changes in the rat brain (brain region). The first of the study showed that normal (unstressed) animals increased exploratory activity dose-dependently. In the present study, psychological deficits and cognitive alteration disrupted serotonin neurotransmission and imbalanced oxidant-antioxidant levels were found in immobilized rats. Acute immobilization stress significantly decreased the time spent in open arm and lightbox in EPM and LDA, respectively, which indicates anxiety-like symptoms. The increased immobility time decreased swimming, and climbing time in FST following immobilization is representing depression-like behavior. Escape latency reduced after $60 \mathrm{~min}$ and $24 \mathrm{~h}$ of training in the MWM task indicating acute stress situations improve cognitive behavior. The anxiolytic, antidepressant, and improved memory functions observed in animals treated with a selected dose of 
M. madrespatana fruit peel powder $(2000 \mathrm{mg} / \mathrm{kg} /$ day $)$. The findings are related to the attenuation of immobilized stress-induced increased lipid peroxidation and decreased antioxidant mechanism by $M$. madrespatana. Levels of ACh in the hippocampus increased while the activity of AChE significantly decreased by M. madrespatana, which indicates cognition improvement. After single immobilization stress, normalization in serotonin metabolism by M. madrespatana suggests anti-stress property of M. madrespatana.

Stress-related psychiatric illnesses are evident as the malfunction of the antioxidant system. Oxidative stress plays a major role in the development of stress-induced behavioral deficits (anxiety and depression) in both human models [40] and experimental animal models [41,42]. An uncontrollable stress situation produces behavioral, neurochemical, and biochemical impairment [30,31]. The present study shows that immobilization stress-induced behavioral deficits such as depression-like symptoms measured by FST, anxiety-like behavior measured by LDA/EPM, and memory impairment (STM and LTM) measured by MWM tests. Behavioral decline (anxiety and depression) and cognitive impairment are the significant features of stress-induced neuronal oxidative stress [28,31]. In the present work, rats exposed to immobilization stress exhibited anxiety-like symptoms by decreasing time spent in an open arm (Figure 2) and light compartment (Figure 3). Similarly, depression-like symptoms were exhibited by increased immobility time while decreasing swimming and climbing time in FST (Figure 4). It is believed that free radical production at the central and periphery level deteriorates the anatomy of the cell and produces peroxidation of the cell membrane's lipid contents [43]. Damage of neuronal cells leads to physiological malfunction of the brain, which may be linked with various behavioral deficits (anxiety and depression). Extensive studies also relate stress-induced oxidative stress to neuroinflammation. It is reported earlier that a stress situation also provokes the synthesis of inflammatory cytokines [44], which may worsen the normal situation and alter the behavioral responses. The activation of inflammatory events following physical and psychological stress burden along with the environmental stress produces cytokines and other inflammatory mediators, which are involved in the development of behavioral impairment and neurodegenerative disorders [45]. Therefore, anxiety-/depression-like behavior observed in the present study is due to increased oxidative stress markers (Figure 6) and inflammatory responses in rats experienced to immobilization stress. It is apparent that repeated administration of $M$. madrespatana peel powder dose-dependently increased exploratory activity in the novel and familiar environment in normal/unstressed animals (Figure 1). Moreover, the selected dose of $M$. madrespatana exhibited increased time spent in lightbox and open arm of LDA (Figure 2) and EPM (Figure 3), respectively, and decreased immobility and increased swimming and climbing time (Figure 4) in both unstressed and stressed animals. It is indicated that the selected dose of M. madrespatana increased motor behavior in unstressed animals (Figures 1-3) as well as in stressed (Figures 2 and 3) animals, and produced anxiolytic and antidepressant effects. Increased oxidative stress stimulates the hypothalamic-pituitary-adrenal axis (HPA-axis), which causes the further release of glucocorticoids [46]. The enhanced release of glucocorticoids may also involve stress-induced behavioral alteration [46,47].

It is well documented that an imbalance between pro-oxidant and antioxidant causes various diseases such as anxiety and depression [48]. The natural cellular antioxidant enzyme SOD, CAT, and GPx fight against ROS production [49] and produce protective effects against various threats/diseases [50]. The present study also showed that single immobilization stress imbalanced the normal natural environment at the cellular level and increased lipid peroxidation/malondialdehyde (Figure 6) and decreased antioxidant enzymes (SOD, CAT, and GPx, Figure 7). Numerous studies also showed free radical production become enhanced and the antioxidant mechanism becomes suppressed in anxiety and depression in humans [40] as well as in animal studies [51]. Various treatments are available, which produce anxiolytic and anti-depressive effects by increasing the antioxidant mechanism and diminishing oxidative stress markers. The available treatment, which is reported until the date are 5-HT-1A agonist such as buspirone [47], 8-OH-DPAT [52], etc. Various parts of plants such as Allium cepa peel [31], Banana fruit pulp, and peel [51], etc., and an active compound, which are 
present in various plants such as quercetin [40], gallic acid [42], etc. Previously, it was reported that leaf extract of $M$. madrespatana have anxiolytic [53] anti-inflammatory [54] and antioxidant [53] effects. Having potent antioxidant $M$. madrespatana enhanced free radical scavenging activity and improved the antioxidant enzyme system $[53,54]$. The present study showed that $M$. madrespatana peel powder improves immobilization stress-induced antioxidant enzymes by increasing SOD, CAT, and GPx (Figure 7) and decreasing MDA levels (Figure 6). These results indicating that single immobilization stress-induced oxidative stress is protected by repeated administration of $M$. madrespatana peel powder possibly via its antioxidant effects.

Serotonin neurotransmission is an important element of the stress response [55]. It was reported earlier that acute stress enhances 5-HT function [40] and increases 5-HT levels in the whole brain [31,40] and various regions of the rat's brain (such as hippocampus, [56]). Dysfunction of serotonergic neurotransmission produces various psychiatric ailments including anxiety [57], depression [58], and cognitive impairment [59]. Increased levels of 5-HT enhancing cognitive function [31,40] and exhibiting anti-depressive behavior [60], however, reduced concentration of 5-HT in the brain [30], and in the hippocampus [33] by altering memory function. Results of the present study showed that the administration of M. madrespatana decreased 5-HT and 5-HIAA levels in immobilized rats than water-treated rats (Figure 9) and proved its anxiolytic property. Apart from that, the reduction of 5-HT and its metabolite was smaller in M. madrespatana-treated stressed animals than unstressed animals (Figure 9). In the present study, 5-HT turnover was found comparable in M. madrespatana-treated unstressed animals and streamed animals (Figure 9). Although memory improvement (Figure 5) was found in both M. madrespatana-treated stressed rats and unstressed rats, it was more improved in M. madrespatana-stressed rats than unstressed rats, which may be due to a smaller decrease of 5-HT and 5-HIAA levels in M. madrespatana-stressed animals (Figure 9). Similarly, the anti-depressive effect of M. madrespatana was observed in both stressed and unstressed rats. It is reported earlier that the whole plant of M. madrespatana contains an alkaloid, terpenoid, flavonoid, and phenolic compounds [61] and the potential role of $M$. madrespatana as an antioxidant is due to the presence of these phytochemicals, which are involved in its anxiolytic, antidepressant, and memory-enhancing effects.

$\mathrm{AChE}$ is a degradative enzyme and a biomarker to determine the cognitive function. ACh is a key neurochemical, which is concerned with memory and learning [62]. Previously, it has reported that acute stress increases the release of $\mathrm{ACh}$ in the hippocampus [63] and modulates the genes that regulate ACh availability after stress and blockade of AChE [64]. Single immobilization increases the ACh availability in the synapse and enhances memory function [64] as observed increased levels of ACh in our study (Figure 10). The previous report showed that single immobilization stress decreased AChE activity [31] and decreased latency escape, which signifies improved memory in these rats. The present result on AChE activity (Figure 8) and ACh levels (Figure 10) are consistent with the previous report [31,40]. Although acute immobilization stress increased oxidative stress (Figure 5), memory improvement as observed in the present study may be due to increased cholinergic function and antioxidant effect of M.M. Previously, various phytochemicals such as gallic acid [42], quercetin [40], and curcumin [65] decreased AChE activity and increased the availability of ACh with improved memory function. It may be postulated that M.M. peels involved in neuronal plasticity by its free radical scavenging potential increase the ACh levels (Figure 10), and produce an inhibitory effect on AChE activity (Figure 8), as observed in the present results. Single immobilization stress and M. madrespatana peel powder have the potential to improve cognitive function via its antioxidant effects, which is the novelty of the present study.

\section{Conclusions}

It is concluded that the present research supports the antioxidant potential of M. madrespatana as reported previously, which protects against single immobilization stress-induced anxiety and depression-like behaviors in rats. Besides, M. madrespatana also involved in the regulation of serotonin function and produces anxiolytic, antidepressant, and memory-enhancing effects. These consequences 
offer the pharmacological indication of folkloric practices of this plant for some neurological disorders. It is suggested that daily intake of $M$. madrespatana peel could be an enhanced antioxidant system of the body and a potential medication for the daily stress-based situation. However, in the future, more studies could be performed to evaluate the effect of $M$. madrespatana on female rats and using chronic stress conditions.

Author Contributions: N.S. designed the study and the experiments. A.A. carried out the experiments. R.U. and A.B. analyzed the data. N.S. and A.A. prepared and edited the manuscript. All authors approved it. All authors have read and agreed to the published version of the manuscript.

Funding: The authors extend their appreciation to the Research Supporting Project Number (RSP-2020/110), King Saud University Riyadh, Saudi Arabia for financial support.

Conflicts of Interest: The authors report no conflict of interest.

\section{References}

1. Chovatiya, R.; Medzhitov, R. Stress, inflammation, and defense of homeostasis. Mol. Cell 2014, 54, 281-288. [CrossRef]

2. De Kloet, E.R.; Joëls, M.; Holsboer, F. Stress and the brain: From adaptation to disease. Nat. Rev. Neurosci. 2005, 6, 463-475. [CrossRef] [PubMed]

3. Sahin, E.; Gümüslü, S. Immobilization stress in rat tissues: Alterations in protein oxidation, lipid peroxidation and antioxidant defense system. Comp. Biochem. Physiol. C Toxicol. Pharmacol. 2007, 144, 342-347. [CrossRef]

4. Miyata, S.; Taniguchi, M.; Koyama, Y.; Shimizu, S.; Tanaka, T.; Yasuno, F.; Yamamoto, A.; Iida, H.; Kudo, T.; Katayama, T.; et al. Association between chronic stress-induced structural abnormalities in Ranvier nodes and reduced oligodendrocyte activity in major depression. Sci. Rep. 2016, 6, 23084. [CrossRef] [PubMed]

5. Vale, W.W.; Spiess, J.; Rivier, C.; Rivier, J. Characterization of a 41-residue ovine hypothalamic peptide that differential environmental modulations on locomotor activity, exploration and spatial behaviour in young and old rats. Physiol. Behav. 1981, 59, 265-271.

6. Musazzi, L.; Milanese, M.; Farisello, P.; Zappettini, S.D. Acute stress increases depolarization-evoked glutamate release in the rat prefrontal/frontal cortex: The dampening action of antidepressants. PLoS ONE 2010, 5, e8566. [CrossRef]

7. Dong, K.; Wu, M.; Liu, X.; Huang, Y.; Zhang, D.; Wang, Y.; Yan, L.J.; Shi, D. Glutaredoxins concomitant with optimal ROS activate AMPK through S-glutathionylation to improve glucose metabolism in type 2 diabetes. Free Radic. Biol. Med. 2016, 101, 334-347. [CrossRef]

8. Samarghandian, S.; Azimi-Nezhad, M.; Afshari, R.; Farkhondeh, T.; Karimnezhad, F. Effects of buprenorphine on balance of oxidant/antioxidant system in the different ages of male rat liver. J. Biochem. Mol. Toxicol. 2015, 29, 249-253. [CrossRef]

9. Ali, S.N.; Ahmad, M.K.; Mahmood, R. Sodium chlorate, A herbicide and major water disinfectant byproduct, generates reactive oxygen species and induces oxidative damage in human erythrocytes. Environ. Sci. Pollut. Res. Int. 2017, 24, 1898-1909. [CrossRef]

10. Samarghandian, S.; Azimi-Nezhad, M.; Samini, F.; Farkhondeh, T. Chrysin treatment improves diabetes and its complications in streptozotocin-induced diabetic rats. Can. J. Physiol. Pharmacol. 2016, 94, 388-393. [CrossRef]

11. Huan, C.; Jiang, L.; An, X.; Yu, M.; Xu, Y.; Ma, R.; Yu, Z. Potential role of reactive oxygen species and antioxidant genes in the regulation of peach fruit development and ripening. Plant Physiol. Biochem. 2016, 104, 294-303. [CrossRef] [PubMed]

12. Samarghandian, S.; Borji, A.; Tabasi, S.H. Effects of Cichorium intybus linn on blood glucose, lipid constituents and selected oxidative stress parameters in streptozotocin-induced diabetic rats. Cardiovasc. Hematol. Disord. Drug Targets 2013, 13, 231-236. [CrossRef] [PubMed]

13. Baradaran, A.; Rabiei, Z.; Rafieian, M.; Shirzad, H. A review study on medicinal plants affecting amnesia through cholinergic system. J. Herbmed. Plarmacol. 2012, 1, 3-9.

14. Rahnama, S.; Rabiei, Z.; Alibabaei, Z.; Mokhtari, S.; Rafieian-kopaei, M.; Deris, F. Antiamnesic activity of Citrus aurantium flowers extract against scopolamine-induced memory impairments in rats. Neurol. Sci. 2014, 36, 553-560. [CrossRef] [PubMed] 
15. Haq, M.Z.; Riaz, M.; Saad, B. Anthocyanins and Human Health, Springer Briefs in Food, Health and Nutrition; Springer: New York, NY, USA, 2016; pp. 1-19.

16. Mamun-or-Rashid, A.N.M.; Hossain, M.S.; Hassan, N.; Dash, B.K.; Sapon, M.A.; Sen, M.K. A review on medicinal plants with antidiabetic activity. Pharmacogn. Phytochem. 2014, 3, 149-159.

17. Thabrew, M.I.; Gove, C.D.; Hughes, R.D. Protection against galactosamine and tert-butyl hydroperoxide induced hepatocyte damage by Melothria maderaspatana extract. Phytother. Res. 1995, 9, 513-517. [CrossRef]

18. Petrus, A.J.A. Mukia maderaspatana (L.) M. Roemer-A review of its global distribution, phytochemical profile and antioxidant capacity. Asian J. Chem. 2012, 24, 23612368.

19. Priya, G.S.; Radhika, R.; Siddhuraju, P. Antioxidant and antimicrobial activity of traditional indian leavesy vegetables: Mukia maderaspatana and Solanum trilobatum. Int. J. Pharm. Pharm. Sci. 2012, 4, 513-521.

20. Ramakrishnamacharya, C.H.; Krishnaswamy, M.R.; Rao, R.B.; Vishwanathan, S. Anti-inflammatory efficacy of Melothria maderaspatana in active rheumatoid arthritis. Clin. Rheumatol. 1996, 15, 214-215. [CrossRef]

21. Raja, B.; Kaviarasan, K.; Arjunan, M.M.; Pugalendi, K.V. Effect of Melothria maderaspatana leaf-tea consumption on blood pressure, lipid profile, anthropometry, fibrinogen, bilirubin and albumin levels in patients with hypertension. J. Altern. Complement. Med. 2007, 13, 349-354. [CrossRef]

22. Srilatha, B.R.; Ananda, S. Antidiabetic effects of Mukia maderaspatana and its phenolics: An in-vitro study on gluconeogenesis and glucose uptake in rat tissues. Pharm. Biol. 2014, 52, 597-602. [CrossRef] [PubMed]

23. Bocarsly, M.E.; Barson, J.R.; Hauca, J.M.; Hoebel, B.G.; Leibowitz, S.F.; Avena, N.M. Effects of perinatal exposure to palatable diets on body weight and sensitivity to drugs of abuse in rats. Physiol. Behav. 2012, 107, 568-575. [CrossRef] [PubMed]

24. Hemalatha, S.; Wahi, A.K.; Singh, P.N.; Chansouria, J.P.N. Evaluation of anti-hyperglycemic and free radical scavenging activity of Melothria maderaspatana Linn. in streptozotocin-induced diabetic rats. Afr. J. Pharm. Pharmacol. 2010, 4, 817-822.

25. Pandey, D.; Pandey, S.; Hemalatha, S. Hypolipidemic activity of aqueous extract of Melothria maderaspatana. Pharmacol. Online 2010, 3, 76-83.

26. Vadivelan, R.; Dhanabal, S.P.; Mohan, P.; Shanish, A.; Elango, K.; Suresh, B. Antidiabetic activity of Mukia maderaspatana (L.) Roem in alloxan induced diabetic rats. Res. J. Pharmacol. Pharmacodyn. 2010, 2, 78-80.

27. Saher, S.; Ali, S.A.; Sakle, N.S.; Khan, S.W. Allium cepa attenuates ischemia reperfusion induced brain injury. Int. J. Pharmaceutical. Res. Allied. Sci. 2015, 4, 59-68.

28. Samad, N.; Tariq, S.; Mahmood, A.; Imran, I.; Alqahtani, F. Reversal of repeated noise stress-induced behavioral, cognitive, neuroendocrine response and oxidative parameters by Abelmoschus esculentus (Okra) root powder in rats. Pak. J. Pharm. Sci. 2020, 33, 1221-1232.

29. Tabassum, S.; Ahmad, S.; Madiha, S.; Khaliqm, S.; Shahzadm, S.; Batool, Z.; Haider, S. Impact of oral supplementation of Glutamate and GABA on memory performance and neurochemical profile in hippocampus of rats. Pak. J. Pharm. Sci. 2017, 30, 1013-1021.

30. Samad, N.; Parveen, T.; Haider, S.; Haleem, D.J. Attenuation of restraint induced behavioral deficits by buspirone and propranolol in rats. J. Coll. Physicians. Surg. Pak. 2005, 15, 795-798.

31. Samad, N.; Saleem, A. Administration of Allium cepa L. bulb attenuates stress-produced anxiety and depression and improves memory in male mice. Metab. Brain Dis. 2018, 33, 271-281. [CrossRef]

32. Porsolt, R.; Enna, S.J.; Malick, J.B.; Richelson, E. Behavioral despair. In Antidepressants: Neurochemical, Behavioral and Clinical Perspectives; Raven Press New York: New York, NY, USA, 1981; pp. 121-139.

33. Haider, S.; Naqvi, F.; Batool, Z.; Tabassum, S.; Perveen, T.; Saleem, S.; Haleem, D.J. Decreased Hippocampal 5-HT and DA Levels Following Sub-Chronic Exposure to Noise Stress: Impairment in both Spatial and Recognition Memory in Male Rats. Sci. Pharm. 2012, 80, 1001-1011. [CrossRef]

34. Chow, C.K.; Tappel, A.L. An enzymatic protective mechanism against lipid peroxidation damage to lungs of ozone-exposed rats. Lipids 1972, 7, 518-524. [CrossRef] [PubMed]

35. Naskar, S.; Islam, A.; Mazumder, U.K.; Saha, P.; Haldar, P.K.; Gupta, M. In Vitro and In Vivo Antioxidant Potential of Hydromethanolic Extract of Phoenix dactylifera Fruits. J. Sci. Res. 2010, 2, 144-157. [CrossRef]

36. Pari, L.; Latha, M. Protective role of Scorparia dulcis plant extract on brain antioxidant status and lipid peroxidation in STZ diabetic male wistar rats. BMC 2004, 6, 16.

37. Flohe, L.; Gunzler, W.A. Assays of glutathione peroxidase. In Methods in Enzymology; Academic Press: Cambridge, MA, USA, 1984; pp. 114-120. 
38. Ellman, G.L.; Courtney, K.D.; Andres, V.; Featherstone, R.M. A new and rapid colorimetric determination of acetylcholinesterase activity. Biochem. Pharmacol. 1961, 7, 88-95. [CrossRef]

39. Liaquat, L.; Sadir, S.; Batool, Z.; Tabassum, S.; Shahzad, S.; Afzal, A.; Haider, S. Acute aluminum chloride toxicity revisited: Study on DNA damage and histopathological, biochemical and neurochemical alterations in rat brain. Life Sci. 2019, 217, 202-211. [CrossRef]

40. Samad, N.; Saleem, A.; Yasmin, F.; Shehzad, M.A. Quercetin protects against stress-induced anxiety- and depression-like behavior and improves memory in male mice. Physiol. Res. 2018, 67, 795-808. [CrossRef]

41. Daglia, M.; Di Lorenzo, A.; Nabavi, S.F.; Sureda, A.; Khanjani, S.; Moghaddam, A.H.; Braidy, N.; Nabavi, S.M. Improvement of Antioxidant Defences and Mood Status by Oral GABA Tea Administration in a Mouse Model of Post-Stroke Depression. Nutrients 2017, 9, 446. [CrossRef]

42. Samad, N.; Jabeen, S.; Imran, I.; Zulfiqar, I.; Bilal, K. Protective effect of gallic acid against arsenic-induced anxiety-/depression- like behaviors and memory impairment in male rats. Metab. Brain Dis. 2019, 34, 1091-1102. [CrossRef]

43. Cho, S.H.; Heo, S.J.; Yang, H.W.; Ko, E.Y.; Jung, M.S.; Cha, S.H.; Ahn, G.; Jeon, Y.J.; Kim, K.N. Protective Effect of 3-Bromo-4,5-Dihydroxybenzaldehyde from Polysiphonia morrowii Harvey against Hydrogen Peroxide-Induced Oxidative Stress In Vitro and In Vivo. J. Microbiol. Biotechnol. 2019, 29, 1193-1203. [CrossRef]

44. Miłkowska, P.; Popko, K.; Demkow, U.; Wolańczyk, T. Pro-inflammatory Cytokines in Psychiatric Disorders in Children and Adolescents: A Review. Adv. Exp. Med. Biol. 2017, 1021, 73-80.

45. Gadek-Michalska, A.; Tadeusz, J.; Rachwalska, P.; Bugajski, J. Cytokines, prostaglandins and nitric oxide in the regulation of stress-response systems. Pharmacol. Rep. 2013, 65, 1655-1662. [CrossRef]

46. Shehu, A.; Magaji, M.G.; Yau, J.; Ahmed, A. Methanol stem bark extract of Adansonia digitata ameliorates chronic unpredictable mild stress-induced depression-like behavior: Involvement of the HPA axis, BDNF, and stress biomarkers pathways. J. Basic Clin. Physiol. Pharmacol. 2019, 30, 3. [CrossRef] [PubMed]

47. Samad, N.; Perveen, T.; Haider, S.; Haleem, M.; Haleem, D.J. Inhibition of restraint-induced neuroendocrine and serotonergic responses by buspirone in rats. Pharmacol. Rep. 2006, 58, 636-642. [PubMed]

48. Perveen, T.; Emad, S.; Haider, S.; Sadaf, S.; Qadeer, S.; Batool, Z.; Sarfaraz, Y.; Sheikh, S. Role of Cyclooxygenase Inhibitors in Diminution of Dissimilar Stress-induced Depressive Behavior and Memory Impairment in Rats. Neuroscience 2018, 370, 121-129. [CrossRef] [PubMed]

49. He, L.; He, T.; Farrar, S.; Ji, L.; Liu, T.; Ma, X. Antioxidants Maintain Cellular Redox Homeostasis by Elimination of Reactive Oxygen Species. Cell Physiol. Biochem. 2017, 44, 532-553. [CrossRef] [PubMed]

50. Lei, X.G.; Zhu, J.H.; Cheng, W.H.; Bao, Y.; Ho, Y.S.; Reddi, A.R.; Holmgren, A.; Arnér, E.S. Paradoxical Roles of Antioxidant Enzymes: Basic Mechanisms and Health Implications. Physiol. Rev. 2016, 96, 307-364. [CrossRef]

51. Samad, N.; Muneer, A.; Ullah, N.; Zaman, A.; Ayaz, M.M.; Ahmad, I. Banana fruit pulp and peel involved in antianxiety and antidepressant effects while invigorate memory performance in male mice: Possible role of potential antioxidants. Pak. J. Pharm. Sci. 2017, 30, 989-995.

52. Haleem, D.J.; Samad, N.; Perveen, T.; Haider, S.; Haleem, M.A. Role of serotonin-1A receptors in restraint-induced behavioral deficits and adaptation to repeated restraint stress in rats. Int. J. Neurosci. 2007, 117, 243-257. [CrossRef]

53. Saravanan, S.; Manokaran, S.; Chand, S. Anxiolytic Activity of Hydro-alcoholic Extract of Mukia maderaspatana Linn. Leaves on Experimental Animals. Jordan J. Pharm. Sci. 2012, 5, 43-50.

54. Petrus, A.J.A. Mukia maderaspatana (Linn.) M. Roemer: A potentially antidiabetic and vasoprotective functional leafy-vegetable. Phcog. J. 2012, 4, 1-12. [CrossRef]

55. Bhattacharya, S.K.; Neeta, D.; Sarkar, M.K. Inhibition of carrageenin-induced pedal oedema in rats by immobilization stress. Res. Exp. Med. 1987, 187, 303-313. [CrossRef] [PubMed]

56. Haleem, D.J. Behavioral deficits and exaggerated feedback control over raphe-hippocampal serotonin neurotransmission in restrained rats. Pharmacol. Rep. 2011, 63, 888-897. [CrossRef]

57. Samad, N.; Batool, F.; Haleem, D.J. Neurochemical and behavioral effects of 8-OH-DPAT following exposure to restraint stress in rats. Pharmacol. Rep. 2007, 59, 173-180.

58. Kraus, C.; Castrén, E.; Kasper, S.; Lanzenberger, R. Serotonin and neuroplasticity-Links between molecular, functional and structural pathophysiology in depression. Neurosci. Biobehav. Rev. 2017, 77, 317-326. [CrossRef] 
59. Pehrson, A.L.; Leiser, S.C.; Gulinello, M.; Dale, E.; Li, Y.; Waller, J.A.; Sanchez, C. Treatment of cognitive dysfunction in major depressive disorder-a review of the preclinical evidence for efficacy of selective serotonin reuptake inhibitors, serotonin norepinephrine reuptake inhibitors and the multimodal-acting antidepressant vortioxetine. Eur. J. Pharmacol. 2015, 753, 19-31. [CrossRef] [PubMed]

60. Samad, N.; Imran, I.; Zulfiqar, I.; Bilal, K. Ameliorative effect of lithium chloride against d-galactose induced behavioral and memory impairment, oxidative stress and alteration in serotonin function in rats. Pharmacol. Rep. 2019, 71, 909-916. [CrossRef] [PubMed]

61. Parameswari, K.; Ananthi, T. Physico-Chemical and Phytochemical Analysis of Mukia maderaspatana L. Res. J. Sci. Technol. 2013, 5, 272-274.

62. Lian, W.; Fang, J.; Xu, L.; Zhou, W.; Kang, D.; Xiong, W.; Jia, H.; Liu, A.L.; Du, G.H. DL0410 Ameliorates memory and cognitive impairments induced by scopolamine via increasing cholinergic neurotransmission in mice. Molecules 2017, 22, 410. [CrossRef]

63. Imperato, A.; Puglisi-Allegra, S.; Casolini, P.; Angelucci, L. Changes in brain dopamine and acetylcholine release during and following stress are independent of the pituitary-adrenocortical axis. Brain Res. 1991, 538, 111-117. [CrossRef]

64. Kaufer, D.; Friedman, A.; Seidman, S.; Soreq, H. Acute stress facilitates long-lasting changes in cholinergic gene expression. Nature 1998, 393, 373-377. [CrossRef] [PubMed]

65. Haider, S.; Naqvi, F.; Batool, Z.; Tabassum, S.; Sadir, S.; Liaquat, L.; Naqvi, F.; Zuberi, N.A.; Shakeel, H.; Perveen, T. Pretreatment with curcumin attenuates anxiety while strengthens memory performance after one short stress experience in male rats. Brain Res. Bull. 2015, 115, 1-8. [CrossRef] [PubMed]

(C) 2020 by the authors. Licensee MDPI, Basel, Switzerland. This article is an open access article distributed under the terms and conditions of the Creative Commons Attribution (CC BY) license (http://creativecommons.org/licenses/by/4.0/). 